\title{
Influence of Storage and Preservation Techniques on Egg-Derived Carotenoids: A Substantial Source for Cutaneous Antioxidants
}

\author{
Clemens Painsi $^{\mathrm{a}, \mathrm{b}}$ Karoline Hesterberg ${ }^{c}$ Jürgen Lademann ${ }^{d}$ \\ Dietrich Knorr $^{e} \quad$ Alexa Patzelt $^{d}$ Staffan Vandersee ${ }^{d}$ Martina C. Meinke ${ }^{d}$ \\ Heike Richter $^{d} \quad$ Adrienne Bob $^{d}$ Fanny Knorr ${ }^{d}$ Franz Quehenberger ${ }^{f}$ \\ Bernhard Lange-Asschenfeldt ${ }^{a}$ d \\ a Department of Dermatology and Venerology, State Hospital Klagenfurt, Klagenfurt, Austria; ${ }^{\mathrm{b}}$ Department of \\ Dermatology and Venerology, Medical University of Graz, Graz, Austria; ' Department of Process Sciences, Berlin \\ University of Technology, Berlin, Germany; ${ }^{\mathrm{d}}$ Department of Dermatology, Allergology and Venerology, Charité - \\ Universitätsmedizin Berlin, Berlin, Germany; ${ }^{e}$ Department of Food Biotechnology and Food Process Engineering, \\ Berlin University of Technology, Berlin, Germany; ${ }^{f}$ Institute for Medical Informatics, Statistics and Documentation, \\ Medical University of Graz, Graz, Austria
}

\section{Keywords}

Antioxidants · Carotenoids · Free radicals · Eggs · Resonance Raman spectroscopy

\begin{abstract}
Antioxidants like carotenoids play a major role in the prevention of the destructive influence of free radicals in our skin. Carotenoids, as well as all other antioxidants, are substantial substances which must be supplied by nutrition. Resonance Raman spectroscopy (RRS) allows measurement of the carotenoid content of eggs, representing a rich carotenoid source in our nutrition. A previous study showed that eggs from organic production contain higher carotenoid levels in contrast to eggs from conventionally housed chicken. The uptake of these organically produced eggs led to an increased antioxidant concentration in the skin.
\end{abstract}

In this study, the effects of different storage modalities, conservation techniques, and the effects of food processing on the carotenoid levels in eggs were investigated with RRS. Common storage modalities and preservation techniques showed only a limited influence on egg-derived carotenoid concentrations. However, a colder environment (at least for shell eggs) and high-pressure preservation had the best preservative influence on the carotenoid content. Surprisingly, food processing such as boiling increased the carotenoid concentration in eggs, whilst broiling destroyed the carotenoids almost completely. In conclusion, RRS is suitable for monitoring egg-derived carotenoid levels, and carotenoid levels in eggs are generally stable under common storage and preservation modalities. Boiling in contrast to broiling of eggs might be superior in terms of carotenoid preservation within food processing.

() 2019 S. Karger AG, Basel

\section{KARGER}

(c) 2019 S. Karger AG, Basel

E-Mail karger@karger.com

www.karger.com/spp
Bernhard Lange-Asschenfeldt, MD

Department of Dermatology, Allergology and Venerology

Charité - Universitätsmedizin Berlin

Charitéplatz 1, DE-10117 Berlin (Germany)

E-Mail bernhard.lange-asschenfeldt@ charite.de 


\section{Introduction}

Free radicals exert destructive effects on the human organism if they exceed a critical level, leading to the damage of cells and compartments as well as elastic fibres of the skin. This damage results in furrows and wrinkles, as visible signs of skin aging. Extrinsic factors such as sun exposure, smoking, and excessive alcohol intake lead to an increased production of free radicals of the human organism, promoting the effects of premature skin aging [1]. The human organism has developed a protective network based on antioxidants, capable of the neutralization of free radicals, thereby preventing tissue damage $[2,3]$. The most common antioxidants are the vitamins A, C, E, and carotenoids, as well as various enzymes $[4,5]$.

Recently, resonance Raman spectroscopy (RRS) has been established for the rapid measurement of carotenoid concentrations in vitro and in vivo, i.e., in the skin, in contrast to more elaborate established techniques such as high-pressure liquid chromatography [6]. Therefore, RRS represents a valuable tool for the determination of the antioxidative network of cutaneous tissue in vivo.

Since the human organism is incapable of synthesizing these antioxidants they need to be incorporated by nutrition, such as through eating fruits and vegetables [7]. However, not only plants represent a rich source of antioxidants, but also meat and, in particular, eggs contain high amounts [8]. In this context it has been shown that particularly egg yolk contains a high concentration of different antioxidants, including carotenoids $[9,10]$ fundamental for the foetal development of the chick. Eggs therefore represent a rich source for antioxidants such as lutein, zeaxanthin, $\beta$-cryptoxanthin, $\beta$-carotene, and lycopene [11]. Egg-derived carotenoid uptake has been shown to lead to a significant increase in the carotenoid concentrations in human skin [9], as already shown for other antioxidant-rich food supplementation, i.e. $\beta$ carotene and lycopene [12].

Recent RRS analyses showed that eggs from chicken that had access to green fodder contained approximately twice as much carotenoid compared to the egg yolk of hens housed in battery cages. These studies highlighted the nutritional value of eggs from chicken that were organically farmed [13].

In this study, we investigated the effects of storage modalities such as temperature and light exposure, food preservation techniques such as pasteurization, highpressure preservation (HPP), high-intensity pulsed electric fields, and treatment with ozonated water on the ca- rotenoid contents of eggs over time. Food processing by boiling and broiling was also investigated with respect to their influence on the carotenoid levels.

\section{Materials and Methods}

\section{RRS Measurements}

The experimental set-up for the in vivo and in vitro detection of carotenoids in biological samples used in the present experiments has previously been described in detail [14].

\section{Source and Preparation of Eggs}

Eggs were purchased from the supermarket Extra, Berlin, Germany, and originated from chicken that were organically farmed according to the guidelines of the European Union (VU/VO EWG 2092/91).

Figure 1 gives an overview of the different conservation and storage experiments of shell and liquid whole eggs (LWE). The conservation experiments were performed only once, after which the eggs (shell and LWE) were stored for 8 weeks without light at $4{ }^{\circ} \mathrm{C}$. The content of carotenoids was quantified prior to conservation and storage procedures and then weekly in two eggs for the given situation over a period of 8 weeks (for conservation techniques and in storage modalities of LWE) or 12 weeks (for storage modalities of shell eggs).

The preservation techniques were performed at the Department of Food Biotechnology and Food Process Engineering, Technische Universität, Berlin, Germany. Shell eggs were pasteurised in a water bath at $59^{\circ} \mathrm{C}$ for $60 \mathrm{~min}$. Liquid eggs were pasteurised using $100 \mathrm{~mL}$ of egg yolk in a tin can placed in a water bath with the can constantly moving. After reaching a temperature of $63^{\circ} \mathrm{C}$, treatment was continued for another $2.5 \mathrm{~min}$ following immediate refrigeration. Ultrasound preservation of the eggs was performed in the ultrasound bath (Sonorex RK 100, Bandelin Electronic KG, Germany) for $10 \mathrm{~min}$ at $105 \mathrm{~W}$ at a frequency of $35 \mathrm{kHz}$. A temperature increase of $5.2^{\circ} \mathrm{C}\left(20.3-25.5^{\circ} \mathrm{C}\right)$ was measured. Ultrasound treatment of the liquid eggs (egg yolk) was performed in a tin can using a sonotrode (UIP 1000, Dr. Hielscher GmbH, Germany) emitting sound waves for $10 \mathrm{~min}$ at $235 \mathrm{~W}$. During this process the temperature increased by $18.5^{\circ} \mathrm{C}\left(19-37.5^{\circ} \mathrm{C}\right)$. Ozone treatment of the eggs was performed at the Leibniz Institut für Agrartechnik Potsdam, Brandenburg, Germany. Eggs were placed in a water bath for 5 min containing ozonated water $\left(3 \mathrm{ppm} \mathrm{O}_{3}\right)$ at a temperature of $8^{\circ} \mathrm{C}$. For this purpose, the water circulated between a water tank and an ozone generator (Legiomed, BWT, Germany), generating $2 \mathrm{~g}$ ozone/h and circulating 1,000 L/h until the final concentration of ozone was achieved. A pressure treatment of $200 \mathrm{~mL}$ of egg yolk was performed in cylinder-shaped plastic bags. At a process temperature of $5{ }^{\circ} \mathrm{C}$, the egg yolk was subjected for $10 \mathrm{~min}$ to a pressure of $250 \mathrm{MPa}$ until an increase of $4^{\circ} \mathrm{C}$ up to a final temperature of $9^{\circ} \mathrm{C}$ was reached. High-intensity pulsed electric field treatment of liquid eggs was performed at a frequency of $5 \mathrm{~Hz}$. The flow through to the treatment cell was $6 \mathrm{~L} / \mathrm{h}$. The entrance temperature of liquid eggs was $21^{\circ} \mathrm{C}$ and the exit temperature was $25^{\circ} \mathrm{C}$, with a field intensity of $21 \mathrm{kV} / \mathrm{cm}$ and energy input of $13 \mathrm{~kJ} / \mathrm{kg}$.

To test the influence of food processing techniques, eggs were either boiled or broiled without any additives. The content of ca-
Painsi et al. 
Fig. 1. Overview of the storage conditions (a) and preservation techniques (b) used for the experiments. * Refrigerated storage (at $4^{\circ} \mathrm{C}$ ) without light.

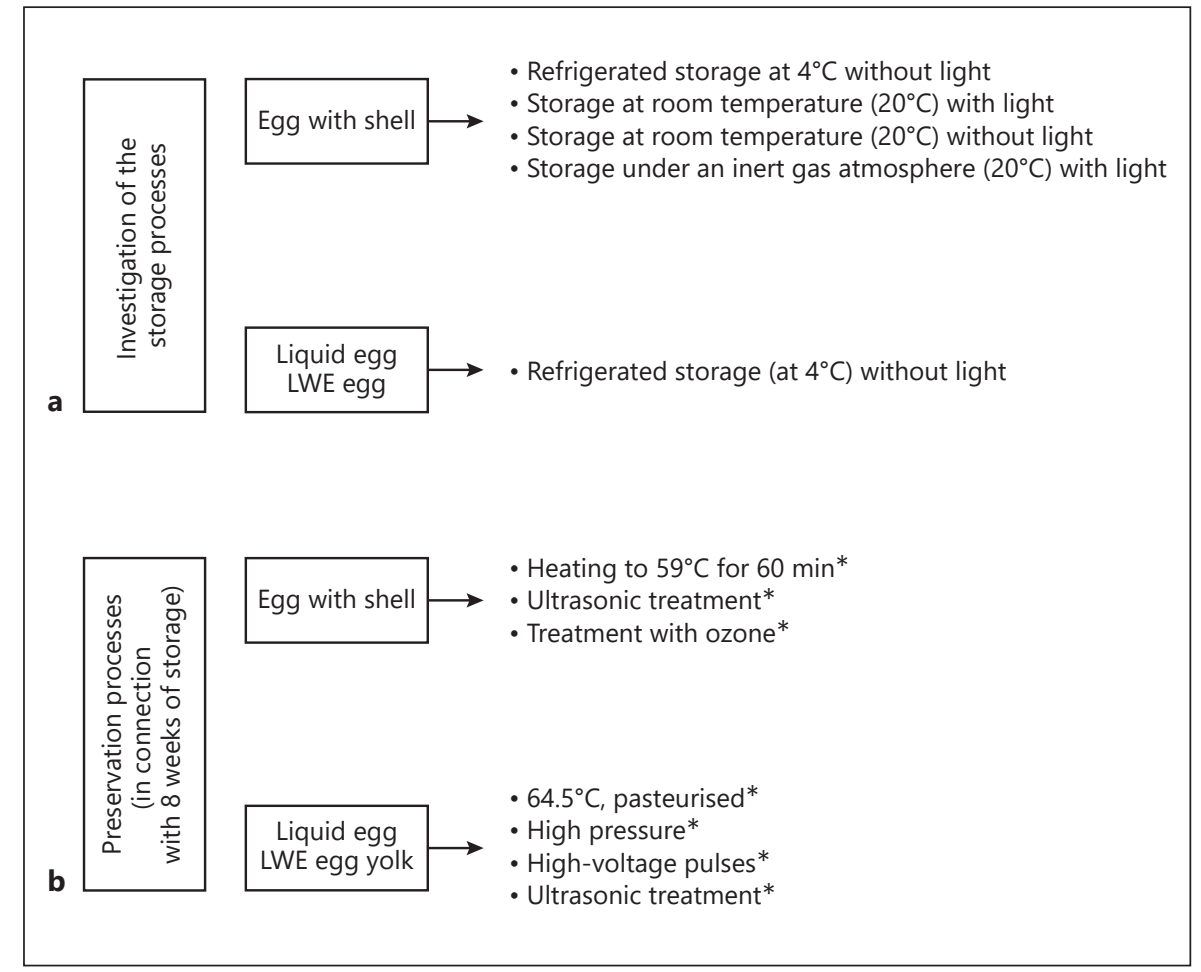

rotenoids was quantified before and after 5 and 10 min of boiling and broiling in eight eggs for the given situation.

\section{Statistical Analyses}

The carotenoid level reduction in eggs depending on storage and conservation techniques was assessed by linear regression. The carotenoid level decrease per week was given as a percentage of the initial content. The effect of food preparation on carotenoid levels is presented as mean values with their standard deviation (SD). The effect of cooking was tested by means of the Wilcoxon rank-sum test. All statistical analyses were performed using SPSS 13.0 and R 3.4.1 (www.r-project.org). $p$ values $<0.05$ were considered statistically significant.

\section{Results}

Effects of Storage and Conservation on the Carotenoid Levels in Eggs

There was a statistically significant decline of carotenoid content in all conservation assays. Within common storage and conservation modalities (Fig. 1), carotenoid levels were shown to be very stable with a mean overall decrease of $2.18 \%$ (for pooled data of all storage modalities) and $1.2 \%$ (for pooled data of all conservation techniques) from baseline per week. Figure 2 depicts in detail the carotenoid level reduction depending on the different storage and conservation techniques as shown by linear regression (change per week and standard error).

\section{Limitations of the Results}

Due to a defect of the Raman spectrometry the values for week 6 could not be used for analysis and the eggs stored under a nitrogen atmosphere were affected by fungus growth, and therefore could not be properly interpreted.

\section{Effects of Food Preparation on the Carotenoid Levels in Eggs}

The mean $\beta$-carotene and lycopene content of eight eggs before boiling was $160 \mu \mathrm{g} / \mathrm{g}$ (SD 4.3) and $58 \mu \mathrm{g} / \mathrm{g}$ (SD $5.5)$, respectively. After $5 \mathrm{~min}$ of boiling these values were $150 \mu \mathrm{g} / \mathrm{g}$ (SD 4.1) and $58 \mu \mathrm{g} / \mathrm{g}$ (SD 2.4), and after $10 \mathrm{~min}$ were $250 \mu \mathrm{g} / \mathrm{g}$ (SD 31) and $99 \mu \mathrm{g} / \mathrm{g}$ (SD 9.7), respectively. Figure 3 a shows that boiling for $5 \mathrm{~min}$ had an impact on the $\beta$-carotene content $(p=0.027)$ but not on the lycopene content $(p=1)$ in the eggs. Interestingly, boiling the eggs for $10 \mathrm{~min}$ led to a massive increase in the carotenoid content ( $\beta$-carotene/lycopene: $p=0.00076 / 0.00077$ ).

The mean $\beta$-carotene and lycopene content of six eggs before broiling was $160 \mu \mathrm{g} / \mathrm{g}$ (SD 6.1) and $54 \mu \mathrm{g} / \mathrm{g}$ (SD 3.6 ), respectively. After $5 \mathrm{~min}$ of broiling these values 


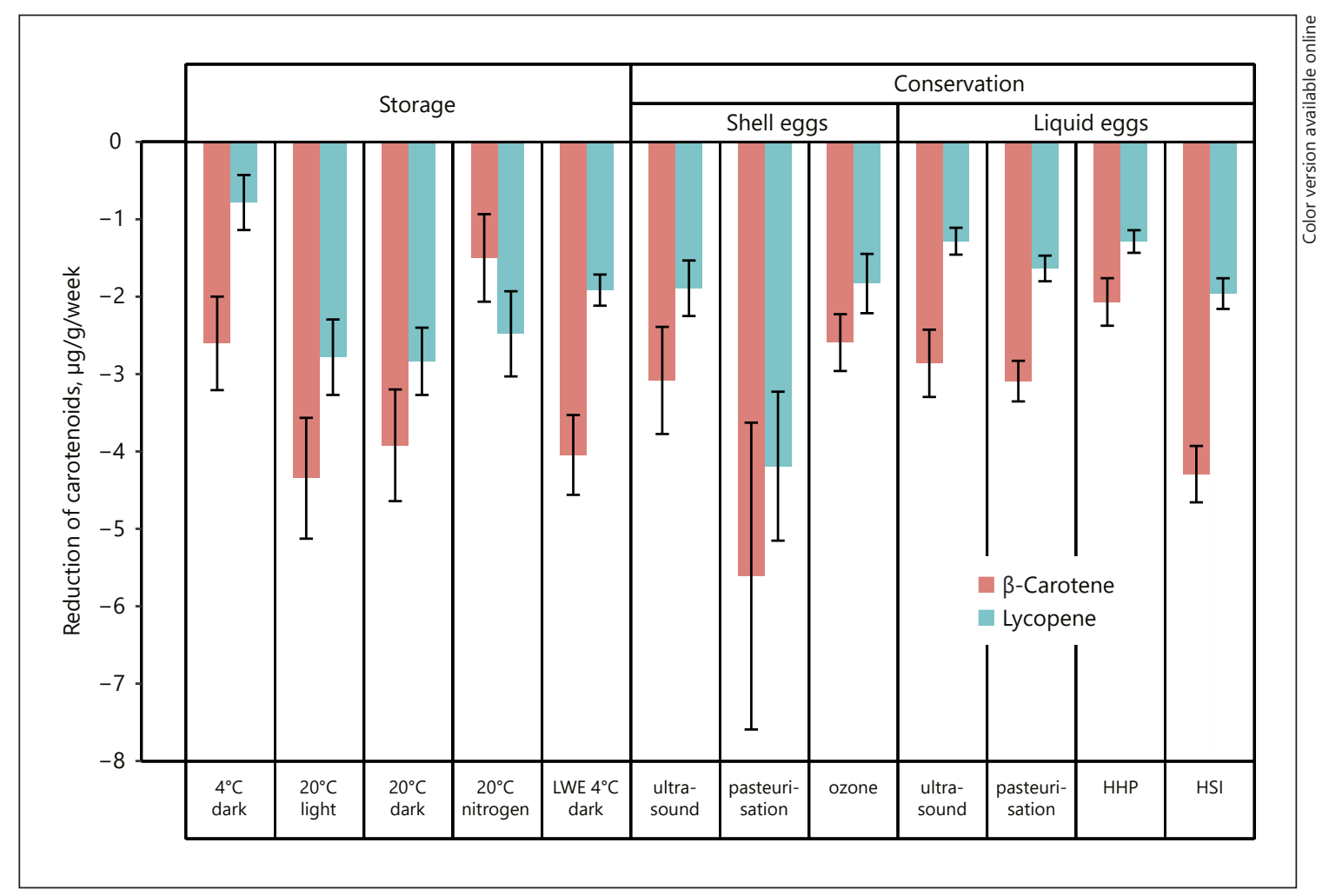

Fig. 2. Carotenoid level reduction in eggs depending on storage and conservation techniques shown by linear regression (change per week and standard error).

were $180 \mu \mathrm{g} / \mathrm{g}$ (SD 68) and $54 \mu \mathrm{g} / \mathrm{g}$ (SD 29), and after 10 min were $1.2 \mu \mathrm{g} / \mathrm{g}$ (SD 0.092) and $1.2 \mu \mathrm{g} / \mathrm{g}$ (SD 0.36), respectively. Figure $3 \mathrm{~b}$ shows no significant increase in carotenoid levels in eggs broiled for $5 \mathrm{~min}$ ( $\beta$-carotene/lycopene: $p=0.34 / 0.34$ ), while after $10 \mathrm{~min}$ of broiling no carotenoids were detected any more $(\beta$-carotene/lycopene: $p=0.00038 / 0.00039$ ).

\section{Discussion}

Our study shows that carotenoid levels in eggs measured by RRS are overall stable with a mean overall decrease of $2.18 \%$ (pooled mean carotenoid reduction of all storage modalities) and $1.2 \%$ (pooled mean carotenoid reduction of all conservation techniques) from baseline per week. A colder environment (at least for shell eggs) and HPP represented the best preservative influence of the carotenoid content in eggs. Surprisingly, food processing such as boiling increased the carotenoid concentration in eggs whilst broiling destroyed the carotenoids almost completely.
Comparing the carotenoid levels in eggs stored at room temperature and at $4{ }^{\circ} \mathrm{C}$, a decrease of $\beta$-carotene as well as lycopene could be observed in the groups of eggs stored at $20^{\circ} \mathrm{C}$ (Fig. 2). These experiments demonstrated the positive preservative influence of a colder environment on the carotenoid content of shell eggs. The refrigerating process seems to support the preservation of the carotenoid lycopene to a higher extent (Fig. 2), which therefore can be considered more stable. It can be concluded that carotenoids are generally well protected when stored under conventional conditions as is typical for household purposes.

HPP preserved the carotenoids better than preservation by high-intensity pulsed electric fields, which led to some carotenoid loss. HPP of food causes a depletion of peroxides (free radicals), thereby lowering the lipid oxidation [15]. High-pressure treatment might protect carotenoids from oxidative degradation. Similar results have been reported from HPP of tomatoes [16], leading to an increased stability of lycopene after applying 500 $\mathrm{MPa}$ pressure in comparison with untreated tomatoes. Since the carotenoid content increased immediately after
Painsi et al. 


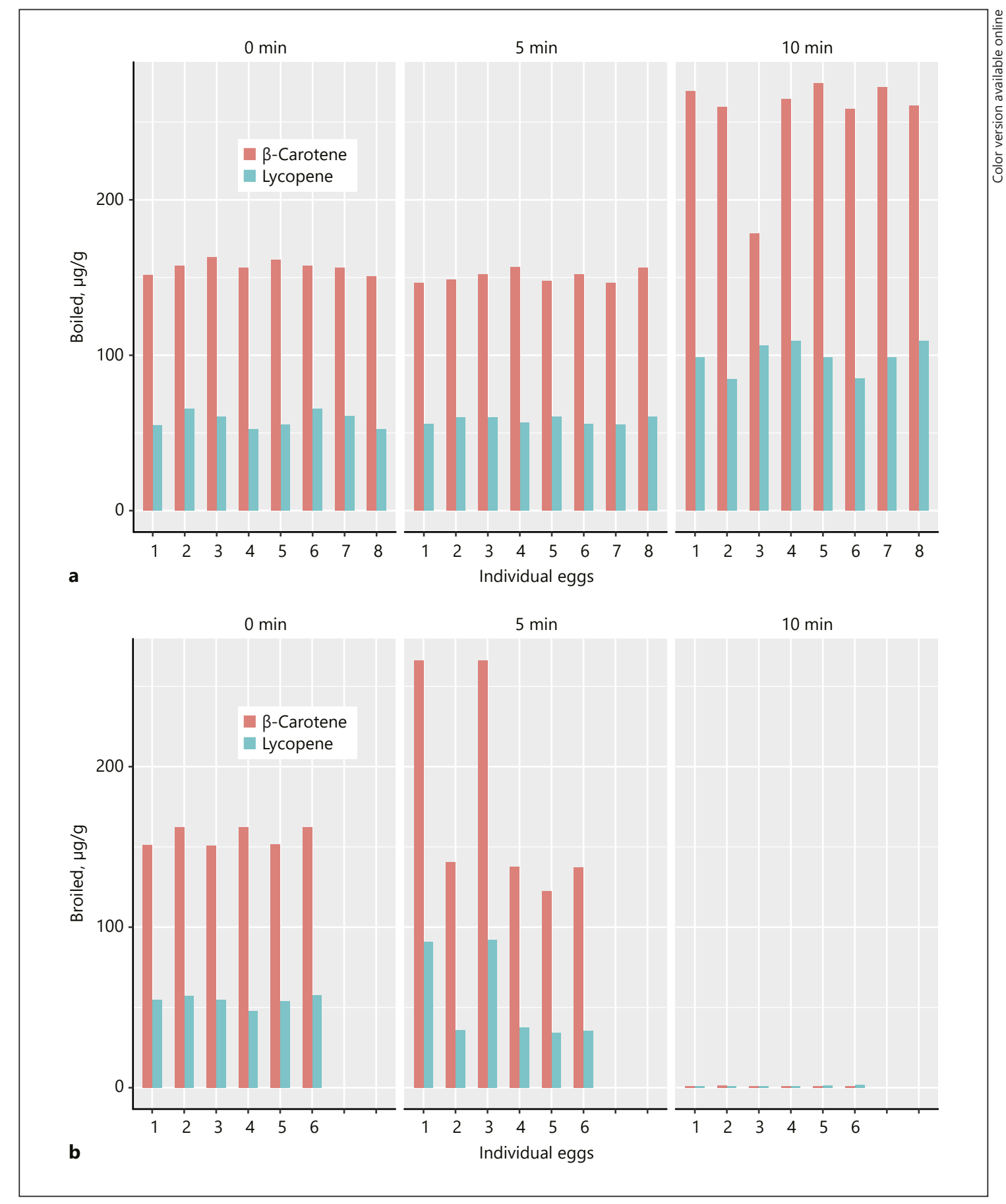

Fig. 3. Effects of food preparation on carotenoid levels in eggs: boiling (a) and broiling (b).

the high-pressure treatment, isomerization processes were discussed [17].

Further research will show whether homogenization and heating generally increase the bioavailability of carotenoids in vegetables. It needs to be elucidated whether
HPP might even increase the carotenoid content in liquid eggs since the potential of HPP to destroy peroxides might help to prevent the destruction of carotenoids. This hypothesis is supported by the comparison of the regression coefficients of untreated liquid eggs and HPP-treat- 
ed liquid eggs, with the latter showing a higher carotenoid content than untreated liquid eggs.

The effect of high-intensity pulsed electric field-treatment on carotenoids has not been fully investigated yet. However, Martin-Beloso et al. [18] reported decreasing carotenoid levels that correlated with increasing electric field densities. Based on our results of the tested preservation techniques, preservation using ultrasound and ozonated water as well as pasteurization appeared not to affect the carotenoid content in the tested eggs, as no significant difference between the regression coefficients of the preservation techniques were observed.

Treatment of liquid eggs with ozonated water is impossible for technical reasons. However, when shell eggs were treated with ozonated water the shell seemed to sufficiently protect the egg from the well-known oxidative effects of the ozone [19]. Zenker et al. [20] preserved orange juice by ultrasound and demonstrated almost no development of free radicals following this procedure. In our experiments we have not observed any decrease in carotenoid levels using ultrasound either.

The mean carotenoid level of eggs increased significantly ( $\beta$-carotene/lycopene: $p=0.00076 / 0.00077$ ) after boiling for $10 \mathrm{~min}$. These effects have been described by Stahl et al. [21], who showed that heat led to isomerization effects of $\beta$-carotene and lycopene as they investigated the influence of heat on carotenoids in tomato products. The same effects have been proven in carrots [22]. Overall, increased temperature leads to cleavage of carotenoid-protein bonds, and thus to increased carotenoid egg levels. The destruction of cells by the heating procedure probably leads to an increased bioavailability of carotenoids [23].

Carotenoid levels in eggs broiled for $5 \mathrm{~min}$ again increased (not significantly, $\beta$-carotene/lycopene: $p=$ $0.34 / 0.34$ ), while after $10 \mathrm{~min}$ of broiling no carotenoids were detected any more ( $\beta$-carotene/lycopene: $p=$ $0.00038 / 0.00039$; Fig. $3 \mathrm{~b}$ ). The heating of the eggs during the first 5 min might lead again to an increased bioavailability by cell destruction and isomerization effects of the carotenoids in some eggs. Because of the direct oxygen influence of light exposure and heat during the broiling procedure, the carotenoids appeared to have been destroyed completely.

Reports indicate a high prevalence of low vitamin $\mathrm{D}$ intake and vitamin D deficiency or inadequate vitamin D status in Europe [24]. Vitamin D plays a well-known role in skeletal health and is considered to modulate innate and adaptive immune function, cardiovascular function, and proliferation and differentiation of both normal and malignant keratinocytes [24]. Diet can also be an important determinant of vitamin D status and eggs are one of the main dietary sources [24]. Interestingly, the vitamin D content of eggs from organically farmed chicken (having access to sunlight) is significantly higher compared with chicken reared indoors [25]. Data on the influence of storage and preservation techniques on egg-derived vitamin D are lacking and should be further investigated.

In conclusion, RRS was suitable for easy and quick analysis of the carotenoid content of eggs and can be conveniently used to monitor the carotenoid levels in food during food preservation procedures. Most preservation techniques, except high-intensity pulsed electric field application, can be efficiently used without affecting the carotenoid content. Some techniques, such as preservation using high pressure, can even increase the carotenoid levels of food. HPP has been shown to eliminate Salmonella bacteria and therefore seems to represent the most promising preservation technique with regard to carotenoid protection. Concerning the processing of the eggs, boiling should be preferred to broiling in order to prevent carotenoid destruction.

\section{Statement of Ethics}

In this study experiments were performed on food only.

\section{Disclosure Statement}

The authors report no conflicts of interest.

\section{References}

1 Handelman GJ, Nightingale ZD, Lichtenstein AH, Schaefer EJ, Blumberg JB. Lutein and zeaxanthin concentrations in plasma after dietary supplementation with egg yolk. Am J Clin Nutr. 1999 Aug;70(2):247-51.

2 Lademann J, Schanzer S, Meinke M, Sterry W, Darvin ME. Interaction between carotenoids and free radicals in human skin. Skin Pharmacol Physiol. 2011;24(5):238-44.

3 Lademann J, Meinke MC, Sterry W, Darvin ME. Carotenoids in human skin. Exp Dermatol. 2011 May;20(5):377-82.

4 Darvin M, Zastrow L, Sterry W, Lademann J. Effect of supplemented and topically applied antioxidant substances on human tissue. Skin Pharmacol Physiol. 2006;19(5):238-47.

5 Darvin ME, Fluhr JW, Schanzer S, Richter $\mathrm{H}$, Patzelt A, Meinke MC, et al. Dermal carotenoid level and kinetics after topical and systemic administration of antioxidants: enrichment strategies in a controlled in vivo study. J Dermatol Sci. 2011 Oct;64(1):53-8.
Painsi et al. 
6 Meinke MC, Darvin ME, Vollert H, Lademann J. Bioavailability of natural carotenoids in human skin compared to blood. Eur J Pharm Biopharm. 2010;76(2):269-74.

7 Halvorsen BL, Holte K, Myhrstad MC, Barikmo I, Hvattum E, Remberg SF, et al. A systematic screening of total antioxidants in dietary plants. J Nutr. 2002 Mar;132(3):461-71.

8 Surai PF, Ionov IA, Kuklenko TV, Kostjuk IA, MacPherson A, Speake BK, et al. Effect of supplementing the hen's diet with vitamin $\mathrm{A}$ on the accumulation of vitamins A and E, ascorbic acid and carotenoids in the egg yolk and in the embryonic liver. Br Poult Sci. 1998 May;39(2):257-63.

9 Hesterberg K, Lademann J, Patzelt A, Sterry W, Darvin ME. Raman spectroscopic analysis of the increase of the carotenoid antioxidant concentration in human skin after a 1-week diet with ecological eggs. J Biomed Opt. 2009 Mar-Apr;14(2):024039.

10 Karadas F, Pappas AC, Surai PF, Speake BK Embryonic development within carotenoidenriched eggs influences the post-hatch carotenoid status of the chicken. Comp Biochem Physiol B Biochem Mol Biol. 2005 Jun;141(2): 244-51.

11 Rosa AP, Scher A, Sorbara JO, Boemo LS, Forgiarini J, Londero A. Effects of canthaxanthin on the productive and reproductive performance of broiler breeders. Poult Sci. 2012 Mar;91(3):660-6.
12 Blume-Peytavi U, Rolland A, Darvin ME, Constable A, Pineau I, Voit C, et al. Cutaneous lycopene and beta-carotene levels measured by resonance Raman spectroscopy: high reliability and sensitivity to oral lactolycopene deprivation and supplementation. Eur J Pharm Biopharm. 2009;73(1):187-94.

13 Hesterberg K, Schanzer S, Patzelt A, Sterry W, Fluhr JW, Meinke MC, et al. Raman spectroscopic analysis of the carotenoid concentration in egg yolks depending on the feeding and housing conditions of the laying hens. J Biophotonics. 2012 Jan;5(1):33-9.

14 Darvin ME, Sterry W, Lademann J. Resonance Raman spectroscopy as an effective tool for the determination of antioxidative stability of cosmetic formulations. J Biophotonics. 2010 Jan;3(1-2):82-8.

15 Ludikhuyze LR, Claeys WL, Hendrickx ME. Effect of temperature and/or pressure on lactoperoxidase activity in bovine milk and acid whey. J Dairy Res. 2001 Nov;68(4):625-37.

16 Qiu HB, Lu XM, Zhou SX, Yang Y, Guo FM. Effect of high tidal volume ventilation and lipopolysaccharide on mitogen-activated protein kinase in rat lung tissue. Chin Med J. 2006 Jan;119(1):53-6.

17 van Het Hof KH, West CE, Weststrate JA, Hautvast JG. Dietary factors that affect the bioavailability of carotenoids. J Nutr. 2000 Mar;130(3):503-6.

18 Martin-Beloso O, Bendicho S, Elez-Martinez P, Barbosa-Canovas GV. Does high-intensity pulsed electric fields induce changes in enzymatic activity, protein conformation and vitamin and flavor stability? In: Barbosa-Canovas GV, Tapia MS, Pilar Cano M, editors. Novel food processing technologies. Washington: CRC Press; 2005.
19 Güzel-Seydim Z, Bever PI Jr, Greene AK. Efficacy of ozone to reduce bacterial populations in the presence of food components. Food Microbiol. 2004;21(4):475-9.

20 Zenker M, Heinz V, Knorr D. Application of ultrasound-assisted thermal processing for preservation and quality retention of liquid foods. J Food Prot. 2003 Sep;66(9):1642-9.

21 Stahl W, Sies H. Bioactivity and protective effects of natural carotenoids. Biochim Biophys Acta. 2005 May;1740(2):101-7.

22 Maiani G, Castón MJ, Catasta G, Toti E, Cambrodón IG, Bysted A, et al. Carotenoids: actual knowledge on food sources, intakes, stability and bioavailability and their protective role in humans. Mol Nutr Food Res. 2009 Sep; 53(S2 Suppl 2):S194-218.

23 Stahl W, Sies H. Uptake of lycopene and its geometrical isomers is greater from heat-processed than from unprocessed tomato juice in humans. J Nutr. 1992 Nov;122(11):2161-6.

24 Spiro A, Buttriss JL. Vitamin D: an overview of vitamin D status and intake in Europe. Nutr Bull. 2014 Dec;39(4):322-50.

25 Guo J, Kliem KE, Lovegrove JA, Givens DI Effect of production system, supermarket and purchase date on the vitamin $\mathrm{D}$ content of eggs at retail. Food Chem. 2017 Apr;221: $1021-5$.
Influence of Storage and Preservation Techniques on Egg-Derived Carotenoids
Skin Pharmacol Physiol 2019;32:65-71 DOI: $10.1159 / 000493147$ 